\title{
Microstructure and mechanical properties of the Inconel 718 superalloy manufactured by selective laser melting
}

\author{
K. Sh. Mukhtarova ${ }^{\dagger, 1}$, R. V. Shakhov' ${ }^{2}$, Sh. Kh. Mukhtarov' ${ }^{2}$, V. V. Smirnov ${ }^{1}$, V. M. Imayev ${ }^{2}$ \\ †kamilla551@gmail.com
}

\author{
${ }^{1}$ Ufa State Aviation Technical University, 12 K. Marx St., Ufa, 450008, Russia \\ ${ }^{2}$ Institute for Metals Superplasticity Problems RAS, 39 S. Khalturin St., Ufa, 450001, Russia
}

\begin{abstract}
The work is devoted to the study of the microstructure and mechanical properties of the nickel base superalloy Inconel 718 manufactured by selective laser melting (SLM). Multiple cycles of heating and cooling during SLM led to the formation of a complex microheterogeneous microstructure. The microstructure of the superalloy manufactured by SLM consisted of elongated $\gamma$ grains with a transversal size of $10-100 \mu \mathrm{m}$ and a longitudinal size of $50-300 \mu \mathrm{m}$, which in its turn consisted

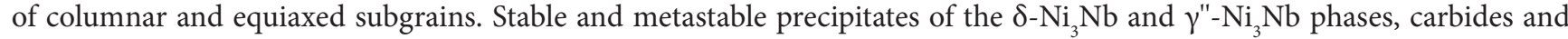
probably oxides, were detected along the subboundaries. The standard heat treatment of the superalloy manufactured by SLM resulted in a partial dissolution of the $\delta$ phase and the metastable $\gamma^{\prime \prime}$ phase during solid solution treatment and precipitation of the dispersed metastable $\gamma^{\prime \prime}$ phase during ageing. The microstructure characterization performed by electron backscatter diffraction technique (EBSD analysis) revealed that the size and elongated form of the $\gamma$ grains was not changed after the heat treatment, the size of the subgrains slightly increased, the fraction of low-angle boundaries (subboundaries) decreased, and the fraction of high-angle grain boundaries increased. Tensile tests were carried out at $T=20-700^{\circ} \mathrm{C}$ for the superalloy samples subjected to standard heat treatment. The tensile direction was parallel to the building direction. The tensile tests showed that the superalloy manufactured by SLM exceeded the requirements of the AMS 5662 certificate for the superalloy Inconel 718 in a hot forged condition subjected to standard heat treatment.
\end{abstract}

Keywords: nickel base superalloys, selective laser melting, microstructure, mechanical properties.

\section{Introduction}

The superalloy Inconel 718 (the Russian analogue is EK61) is an austenitic nickel-based alloy that can withstand high mechanical and thermal loadings at operating temperatures ranging from negative to $700^{\circ} \mathrm{C}$. The superalloy is widely used in rocket and aircraft engines. The conventional processing technologies for manufacturing of parts made of Inconel 718 include the ingot production, wrought processing by hot forging/rolling followed by machining to obtain the desired geometry of the part and the final heat treatment to relieve residual stresses. In the case of a complex shape part, laboriousness and the manufacturing cost become considerable due to laborious machining and low material utilization. It can be reduced through the use of additive technologies, in particular, based on selective laser melting (SLM). However, multiple cycles of heating and cooling with fast solidification during SLM lead to formation of a microheterogeneous microstructure with an increased dislocation density and precipitations of dispersed hardening phases including small carbides and oxides [1-12] that can negatively affect mechanical and service properties of the Inconel 718 superalloy. It is also known that the material obtained by SLM can have pores [13-17]. Therefore, because of specifics of the SLM method, the mechanical (service) properties of the part obtained by SLM can be lower than standard requirements in accordance with quality specifications. In practice, this means that in the case of a part manufactured by SLM out of Inconel 718 the mechanical properties are competitive if they are comparable with the properties of the industrial Inconel 718 superalloy in the wrought condition.

The aim of the present work was to study the microstructure and mechanical properties of the Inconel 718 superalloy produced by SLM. The obtained properties are compared with those of the superalloy in the wrought condition subjected to standard heat treatment in accordance with the AMS 5662 specification.

\section{Material and experimental methods}

The Inconel 718 superalloy produced by SLM had the following chemical composition: Ni-19.8Cr-18.4Fe-5.9Nb3.4Mo-1Ti-0.6Al-0.1Co-0.04C-0.025B (in wt.\%). The initial materials were produced as bars having a round and square cross sections with dimensions of $\varnothing 11 \mathrm{~mm} \times 70 \mathrm{~mm}$ and $11 \times 11 \times 70 \mathrm{~mm}^{3}$. The power of the laser beam, scanning speed, layer thickness, diameter of the laser spot and the distance between the separate passages of the laser beam were chosen to ensure minimal porosity in the produced material. The SLM material was subjected to standard heat treatment. In accordance with the AMS 5662 specification it included solid solution treatment at $980^{\circ} \mathrm{C}(1 \mathrm{~h})$, air cooling, two-stage ageing at $720^{\circ} \mathrm{C}(8 \mathrm{~h})$ and $620^{\circ} \mathrm{C}(8 \mathrm{~h})$, and cooling in air. 
Microstructure examination was carried out using scanning electron microscopy in backscattering electron (BSE) mode. In addition, electron backscatter diffraction (EBSD) analysis was performed with a scan-step size of $1 \mu \mathrm{m}$ to evaluate the SLM material before and after standard heat treatment. EBSD analysis was conducted using the CHANNEL 5 processing software. The grain boundaries having misorientation angles less than $2^{\circ}$ were excluded from the consideration taking into account the measurement accuracy. If the misorientation angles were more than $15^{\circ}$, the grain boundaries were assumed as high-angle ones. For microscopic studies, the samples were ground and then polished at $50 \mathrm{~V}$ in an electrolyte of the composition: $10 \%$ perchloric acid $+90 \%$ butanol.

To conduct tensile tests, the flat samples with a gauge size of $10 \times 3 \times 2 \mathrm{~mm}^{3}$ were prepared. The tensile axis coincided with the building direction during SLM. The tensile tests of the superalloy obtained by SLM and subjected to the standard heat treatment were performed at $20-700^{\circ} \mathrm{C}$ with an initial strain rate of $\dot{\varepsilon}=8.3 \times 10^{-4} \mathrm{~s}^{-1}$. Before testing the samples were subjected to fine grinding of work surfaces.

\section{Results and discussions}

\subsection{Microstructure of the superalloy obtained by SLM}

Optical and electron microscopic observations showed that the material produced by SLM had insignificant porosity in the form of individual small pores. Fig. 1 shows the BSE images of the superalloy in a plane perpendicular to the building direction during SLM (parallel to the layering). One can see that the microstructure consisted of equiaxed $\gamma$ grains with a size of more than $10 \mu \mathrm{m}$. This is agreed with the observations made in [7]. In its turn, $\gamma$ grains consisted of columnar and equiaxed subgrains (Fig. 1b). In $[16,18,19]$, such a microstructure was described as cellular with respect to equiaxed subgrains and dendritic with respect to columnar subgrains. Columnar subgrains, in turn, apparently consisted of equiaxed subgrains $0.5-1 \mu \mathrm{m}$ in size as was also observed in [7]. Bright particles of the $\delta$ phase were located along the $\gamma$ grain boundaries and the subboundaries

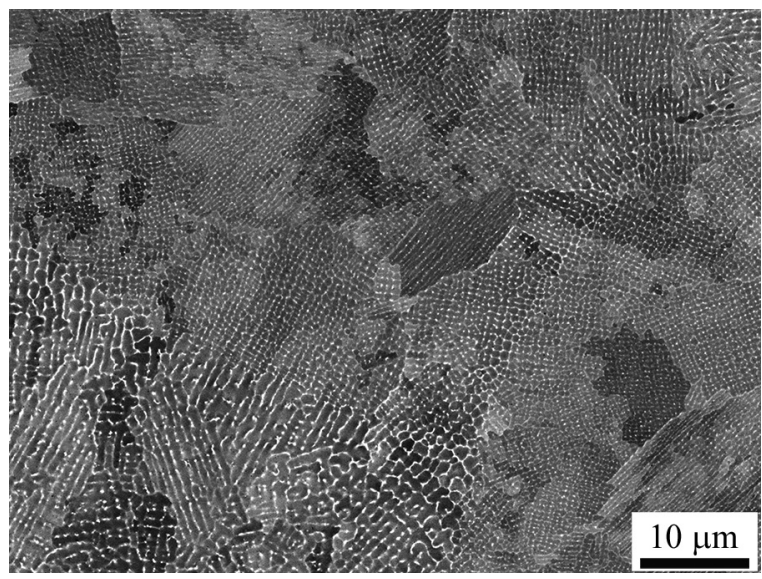

a
(Fig. 1). The dispersed nanoscale $\gamma^{\prime \prime}$ phase was precipitated in subgrains and was visible at high magnifications (Fig. 1b) [8]. Variable contrast of the $\delta$ phase (changing from light to gray) indicates a variable composition of this phase, which was not diffusively equalized during rapid heating, cooling and fast solidification. Along the $\gamma$ grain boundaries, dispersed carbides and probably oxides with a size of about $0.1 \mu \mathrm{m}$ were also detected (Fig. 1b). Note that this is consistent with earlier made observations $[1,3,4,7,8]$. Large carbides with a size of 1-10 $\mu \mathrm{m}$ usually observed in the industrial Inconel 718 superalloy [20] were not revealed in the SLM superalloy.

Fig. 2 represents the EBSD orientation map with corresponding misorientation-angle distribution for grain boundaries obtained for the Inconel 718 superalloy produced by SLM. In Fig. 2 a, the layers are horizontal and the building direction during SLM is vertical. It is seen that elongated $\gamma$ grains were formed in the building direction (perpendicular to the layers) and elongated in the heat sink direction coinciding with the direction of layering (perpendicular to the layers). EBSD analysis revealed a developed substructure in the interior of $\gamma$ grains. This is expressed by increased densities of dislocations and low-angle boundaries observed in the interior of the elongated $\gamma$ grains (Fig. $2 \mathrm{a}$ ). The fraction of high-angle grain boundaries was defined as $46 \%$, i.e. most of the boundaries were low-angle ones. Evaluating the size of elongated $\gamma$ grains using Figs. 1 and 2, one can conclude that the transversal size of $\gamma$ grains was $10-100 \mu \mathrm{m}$ and the length was $50-300 \mu \mathrm{m}$.

Fig. 3 shows the BSE images of the superalloy produced by SLM and subjected to the standard heat treatment. Solid solution treatment was carried out at near the temperature of full dissolution of the $\delta$ phase. One can see that the transversal size of $\gamma$ grains was retained almost unchanged. The sizes of the $\delta$ phase and presumably carbide precipitates located along the $\gamma$ grain boundaries increased, while a number of the precipitates along the subboundaries significantly decreased. The dispersed $\gamma^{\prime \prime}$ precipitates became more visible at high magnifications (Fig. $3 \mathrm{~b}$ ). In general, the volume fraction of the secondary phases decreased indicating that the $\delta$ and $\gamma^{\prime \prime}$ phases were partially dissolved after the standard heat treatment (Figs. 1a and $3 \mathrm{a}$ ). The subgrains became more

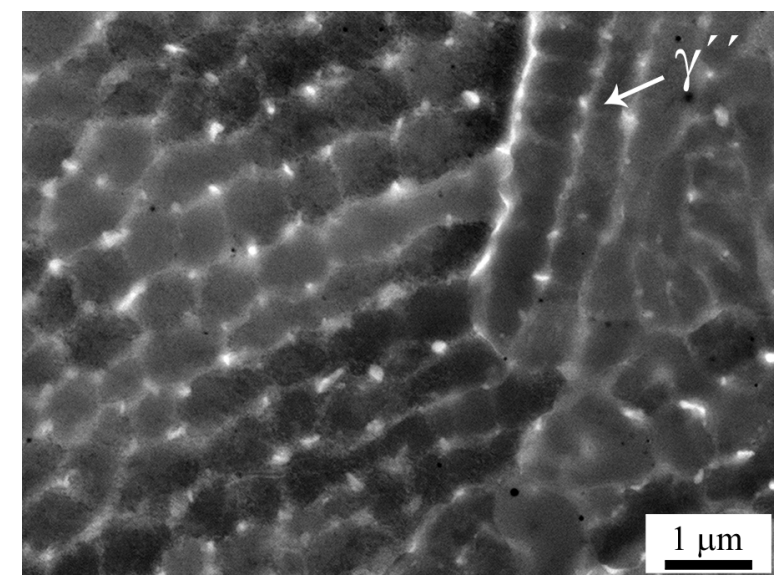

b

Fig. 1. BSE images of the Inconel 718 superalloy in the as-printed condition. The picture was obtained from the plane perpendicular to the building direction during SLM (parallel to layers). The grains shown in (a) consisted of subgrains (b). The $\gamma^{\prime \prime}$ phase precipitates are visible at high magnifications in the interior of subgrains [8]. 


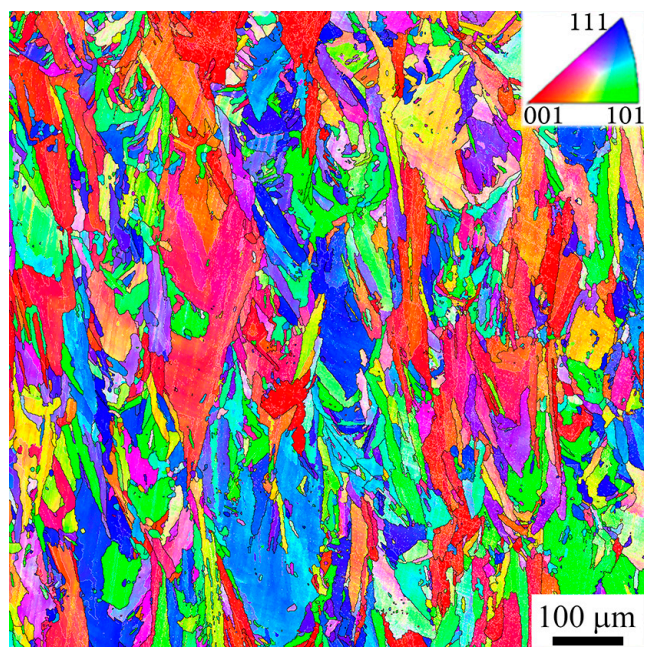

a

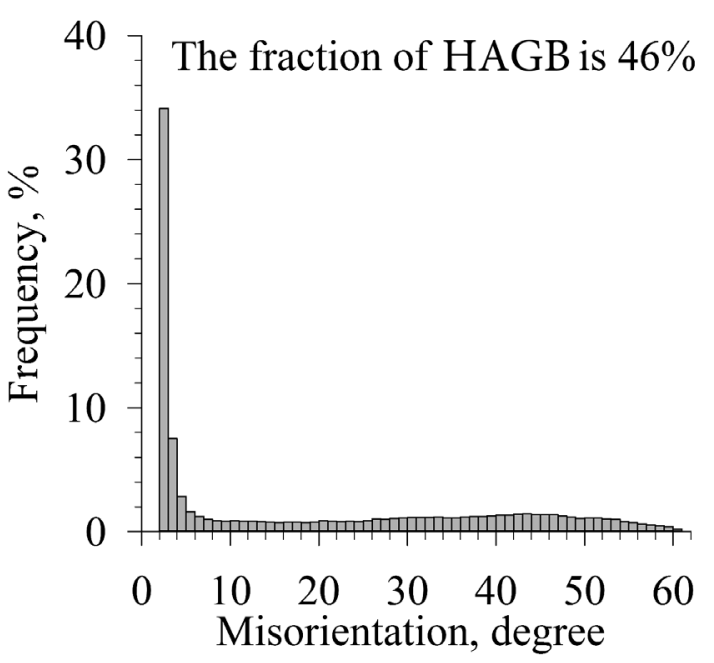

b

Fig. 2. (Color online) EBSD orientation map (a) and corresponding misorientation-angle distribution (b) for grain boundaries obtained for the Inconel 718 superalloy produced by SLM. The layers are horizontal and the building direction is vertical. HAGB designates high-angle grain boundaries.

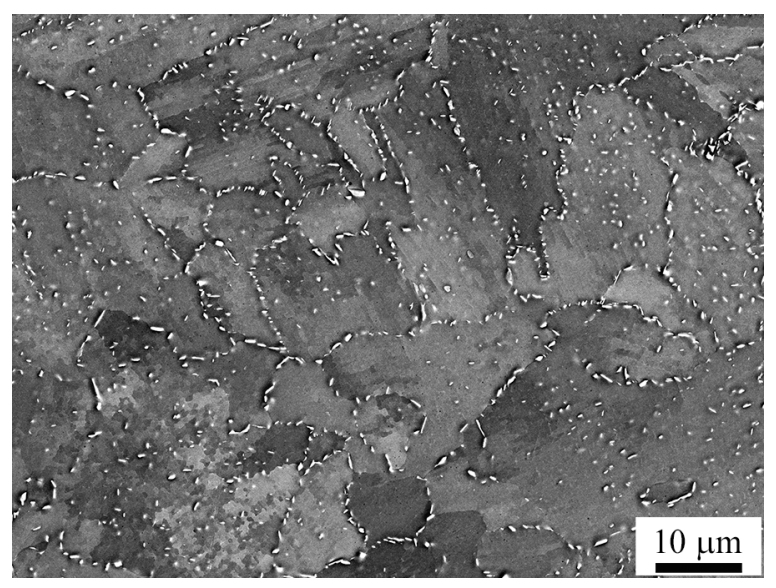

a

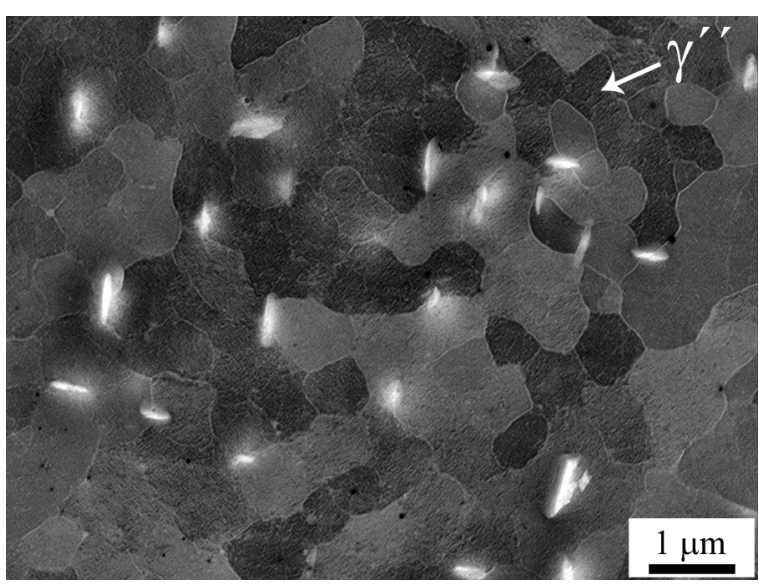

$\mathrm{b}$

Fig. 3. BSE images of the Inconel 718 superalloy manufactured by SLM and subjected to the standard heat treatment. The picture was obtained from the plane perpendicular to the building direction during SLM (parallel to layers). The grains shown in (a) consisted of subgrains (b). The $\gamma^{\prime \prime}$ phase is arrowed.

rounded and equilibrium as compared with the as-printed condition (Fig. 3 b).

Fig. 4 shows the EBSD orientation map and corresponding misorientation-angle distribution for grain boundaries obtained for the Inconel 718 superalloy produced by SLM and subjected to the standard heat treatment. As is seen, the morphology of $\gamma$ grains and their size was not changed as compared to the as-printed condition. At the same time, the number of low-angle grain boundaries in the interior of $\gamma$ grains significantly decreased. As a result, the fraction of high-angle grain boundaries after the heat treatment increased to $66 \%$ (Fig. 4 b).

\subsection{Tensile properties}

Table 1 represents the results of tensile tests of samples of the Inconel 718 superalloy manufactured by SLM and subjected to the standard heat treatment. With increasing the test temperature, the strength properties monotonically decreased. A slight decrease in ductility with increasing the test temperature can be explained by oxidation of samples during its exposure prior and in the course of testing, which occurred more intensively during localization of deformation in a neck. However, the reduction of area with increasing the test temperature increased indicating an increase in the ductile properties. It is worth noting that the tensile properties obtained for the Inconel 718 superalloy produced by SLM and subjected to the standard heat treatment exceeded the requirements of the AMS 5662 specification for the industrial superalloy in the wrought and heat treated condition [4]. The comparison with other works devoted to the Inconel 718 superalloy manufactured by SLM and subjected to standard heat treatment shows that comparable or slightly superior tensile properties were achieved in the present work [11,15].

Thus, microstructure studies and the obtained tensile properties indicate that a high-quality material can be produced by SLM. The SLM material subjected to the standard heat treatment demonstrated quite reasonable tensile properties. Further investigations of mechanical properties will open up possibilities for the wide application of SLM for manufacturing of complex shape parts made of the Inconel 718 superalloy. 
Table 1. Results of tensile tests of the Inconel 718 superalloy manufactured by SLM and subjected to the standard heat treatment.

\begin{tabular}{|c|c|c|c|c|}
\hline \multirow{2}{*}{ Test temperature, ${ }^{\circ} \mathrm{C}$} & \multicolumn{5}{|c|}{ Tensile properties } \\
\cline { 2 - 5 } & YS, MPa & UTS, MPa & $\delta, \%$ & $20.9 \pm 0.5(>12)$ \\
\hline 20 & $1175(>1034)^{\star}$ & $1364(>1276)$ & $16.9 \pm 0.3$ & $34.6 \pm 1.9$ \\
\hline 550 & 1064 & 1176 & $16.0 \pm 0.7$ & $32.8 \pm 1.3$ \\
\hline 600 & 1042 & 1185 & $19.5 \pm 1.0(>12)$ & $31.0 \pm 0.8(>15)$ \\
\hline 650 & $1025(>862)$ & $1126(>1000)$ & $19.3 \pm 1.3$ & $35.8 \pm 1.7$ \\
\hline 700 & 957 & 1011 & 18.6 & - \\
\hline $20[11]$ & 1271 & 1425 & 10.1 & - \\
\hline $650[11]$ & 1042 & 1142 & 20.4 & - \\
\hline $20[15]$ & 1180 & 1400 & 14.2 & - \\
\hline $650[15]$ & 860 & 992 & & \\
\hline
\end{tabular}

${ }^{\star}$ The requirements in accordance with the AMS 5662 specification are indicated in parentheses for the industrial Inconel 718 superalloy in wrought condition subjected to standard heat treatment.

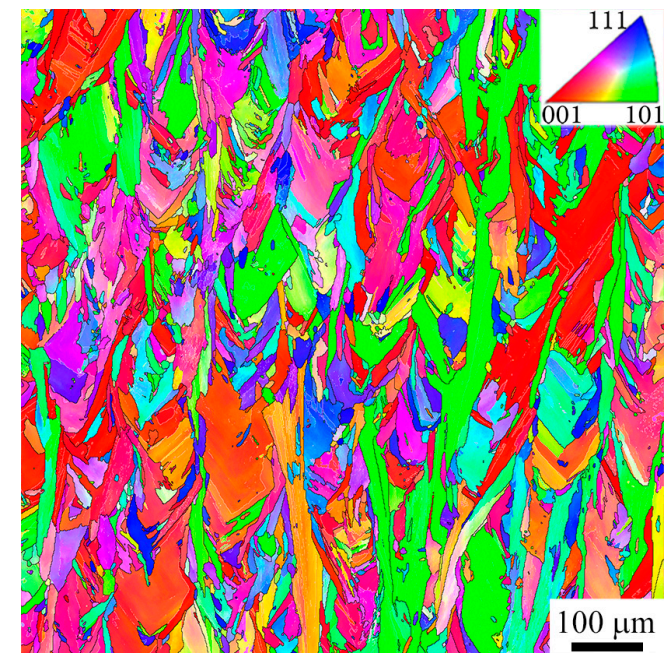

a

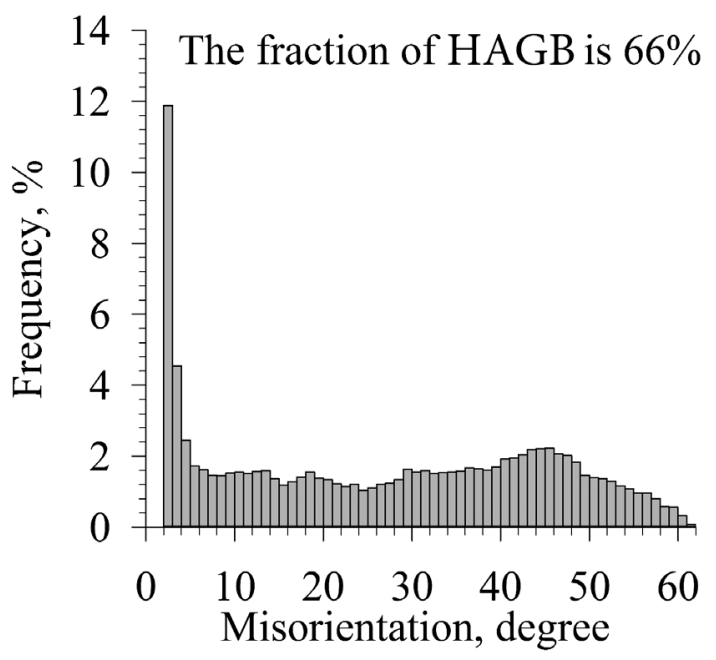

$\mathrm{b}$

Fig. 4. (Color online) EBSD orientation map (a) and corresponding misorientation-angle distribution for grain boundaries (b) obtained for the Inconel 718 superalloy produced by SLM and subjected to the standard heat treatment. The layers are horizontal and the building direction is vertical.

\section{Conclusions}

1. The microstructure and tensile properties of the Inconel 718 superalloy manufactured by SLM and subjected to standard heat treatment have been investigated. It was established that SLM led to formation of non-equiaxed $\gamma$ grains elongated in the direction of building during SLM perpendicular to the layers. A feature of the produced SLM material was a developed dislocation substructure in the interior of $\gamma$ grains as well as the presence of stable and metastable precipitates of the $\delta$ and $\gamma^{\prime \prime}$ phases located along grain and subgrain boundaries ( $\delta$ phase) or in the interior of subgrains ( $\gamma^{\prime \prime}$ phase).

2. The standard heat treatment led to a decrease of the number of low-angle boundaries in the interior of $\gamma$ grains, while the shape and the size of $\gamma$ grains was not changed in comparison with the condition before the heat treatment. The heat treatment promoted the diffusion equalization of the superalloy composition, the dissolution of the secondary dispersed phases along the subboundaries and their precipitation mainly along the grain boundaries.
The volume fraction of the secondary phases after the heat treatment decreased.

3. A study of the tensile properties of the Inconel 718 superalloy manufactured by SLM and subjected to the standard heat treatment showed that they exceeded the requirements of the AMS 5662 specification for the industrial superalloy in the wrought and heat treated condition.

4. The obtained results suggest that the SLM method can be successfully used for manufacturing of parts made of the Inconel 718 superalloy and having mechanical properties, which are not inferior to those of the industrial superalloy in the wrought and heat treated condition.

Acknowledgements. The present study was accomplished according to the state assignment of IMSP RAS (AAAA-A17-117041310215-4). The work was performed using the facilities of the shared services center "Structural and Physical-Mechanical Studies of Materials" at the Institute for Metals Superplasticity Problems of Russian Academy of Sciences. 


\section{References}

1. T. DebRoy, H.L. Wei, J.S. Zuback, T. Mukherjee, J.W. Elmer, J.O. Milewski, A.M. Beese, A. WilsonHeid, A. De, W. Zhang. Progr. Mater. Sci. 92, 112 (2018). Crossref

2. J.P. Oliveira, T.G. Santos, R. M. Miranda. Progr. Mater. Sci. 107, 100590 (2020). Crossref

3. T. Raza, J. Andersson, L.-E. Svensson. Proc. Manufact. 25, 450 (2018). Crossref

4. X. Gong, X. Wang, V. Cole, Z. Jones, K. Cooper, K. Chou. In: Proceedings of the ASME 2015 International Manufacturing Science and Engineering Conference. Charlotte, North Carolina, USA (2015) p. 1.

5. DMLS. Direct Metal Laser Sintering

6. C. Körner. International Materials Reviews. 61 (5), 361 (2016). Crossref

7. W.M. Tucho, P. Cuvillier, A. Sjolyst-Kverneland, V. Hansen. Mater. Sci. Eng. A. 689, 220 (2017). Crossref

8. Y.-L. Kuo, K. Kakehi. Metals. 7, 367 (2017). Crossref

9. L.E. Murr, E. Martinez, K.N. Amato, S.M. Gaytan, J. Hernandez, D. A. Ramirez, P.W. Shindo, F. Medina, R. B. Wicker. J. Mater. Res. Technol. 1, 42 (2012). Crossref

10. X. Wang, K. Chou. Inter. J.Adv. Manuf. Technol. 100, 2147 (2019). Crossref
11. R. Konečná, L. Kunz, G. Nicoletto, A. Bača. Frattura ed Integrità Strutturale. 10 (35), 31 (2016). Crossref

12. C. A. Wade, G. Bertali, T. Withaar, D. Foord, B. Freitag, G. Burke. In: The 16th European Microscopy Congress, Lyon, France (2016) p. 223. Crossref

13. Y. Lu, S. Wu, Y. Gan, T. Huang, C. Yang, L. Junjie, J. Lin. Optics \& Laser Technol. 75, 197 (2015). Crossref

14. M. C. Karia, M. A. Popat, K. B. Sangani. AIP Conference Proceedings. 1859, 020013 (2017). Crossref

15. T. Trosch, J. Strößner, R. Völkl, U. Glatzel. Mater Letters. 164, 428 (2016). Crossref

16. T. Bauer, K. Dawson, A.B. Spierings, K. Wegener. In: Proceedings of the 26th Annual International Solid Freeform Fabrication Symposium. Austin, TX, USA (2015) p. 813. $\underline{\text { Crossref }}$

17. C. Y. Yap, C. K. Chua, Z. L. Dong, Z.H. Liu, D. Q. Zhang, L.E. Loh, S. L. Sing. Appl. Phys. Reviews. 2, 041101 (2015). Crossref

18. A. A. Popovich, V. Sh. Sufiiarov, I. A. Polozov, E. V. Borisov. Key Eng. Mater. 651-653, 665 (2015). $\underline{\text { Crossref }}$

19. S. Raghavan, B. Zhang, P. Wang, C.-N. Sun, M. L. S. Nai, T.Li. Mater. Manufact. Proc. 32 (14), 1588 (2017). Crossref

20. C. T. Sims, N. S. Stoloff, W. C. Hagel. Superalloys II. New York, John Wiley \& Sons (1987) 615 p. 